\section{Sanctions should not apply to biomedical research}

SIR - I was pleased to read your News Feature "The brains trust of Tehran" (Nature $435,264-265$; 2005), which reminded me, and probably many young Iranian scientists raised after the revolution, of our enthusiasm for scientific research at university, despite access to only the most basic of equipment.

It is disappointing for me to see the effects that the sanctions imposed on Iran by the United States are having on basic biomedical research. In the example cited in your News Feature it took four years for the Iranian lab to secure equipment for neuronal recordings. I understand that the United States would not welcome scientific achievements in fields such as nuclear science or space technology for fear that they could be used to make weapons of mass destruction. But I believe other scientific fields, especially biomedical ones, should be exempt from these sanctions.

Local research on endemic diseases such as haemophilias, thalassaemias and oesophageal carcinoma may lead to new preventive and therapeutic insights beneficial to patients in Iran and worldwide; sanctions should not apply to this kind of work. I do not think it is difficult to differentiate such activities from those used to further geopolitical and governmental goals, and I would like to see the US government reconsider some of its scientific embargos against Iran.

Ahmad Jalili

Division of Immunology, Allergy and Infectious Diseases, Department of Dermatology, Medical University of Vienna, General Hospital-AKH, Wăhringer Gürtel 18-20, A-1090, Vienna, Austria

\section{Bioterror killed five in US; guns kill 30,000 a year}

SIR - I read with concern the call for biological scientists to be more careful in how they communicate their work ( ${ }^{\alpha}$ Biologists asked to breed a culture of responsibility in face of terrorism" Nature 435, 860; 2005). Many implements can be used by terrorists to harm people, by far the most common being military-style firearms. Every year in the United States, some 30,000 people are killed by firearms. The only lethal biological attack in the United States was carried out in 2001, using a supply of anthrax that came from a US source and killed five people.

In the United States, every call to restrict access to military-style firearms by civilians is met with fierce opposition from the National Rifle Association (NRA), who prodaim that the Second Amendment prevents any such regulation. When the number of people killed by biological agents gleaned from the scientific literature exceeds the number killed by firearms, perhaps then we should consider restricting that literature in the same way that firearms are restricted. Until then, we should be prepared to uphold the First Amendment and protect the freedom of speech.

To borrow a phrase from the NRA, when can you take away my scientific literature? When you can pry it from my cold dead hand! David R. Whitlock

40 Nash Street, Watertown,

Massachusetts 02472, USA

\section{Ethics debate is what put Newcastle paperin the news}

SIR - Your Editorial "Too much, too soon ${ }^{\text {" }}$ (Nature 435, 538; 2005) deplored the fact that the abstract for our manuscript submitted to Reproductive BioMedicine (RBM) Online became public, before being peer-reviewed, on the same day that a Korean group led by W. S. Hwang announced in a Science paper that it had succeeded in producing eleven embryonic stem-cell lines. We would like to darify our position in this matter.

On 16 May, we submitted a manuscript to RBM Online that had previously been offered to both the British Medical Journal and The Lancet; both journals had declined it after editorial review, daiming insufficient dinical content. At the time of submission to $R B M$ Online, we were not aware that the abstract would be made immediately available online. Learning of this the next day, we asked $R B M$ Online to remove the abstract to prevent public awareness before publication of the Science study. One of us also met Professor Hwang to inform him of our actions and exchange manuscripts. Our paper has now been accepted for publication by $R B M$ Online and will appear, in full, in August.

On 16 May, UK journalists also became aware of the forthcoming publication in Science and contacted us to ask about our progress with nuclear transfer. We did not comment on the Korean breakthrough in advance of its publication, but felt it natural and necessary to say that we had submitted our work and that it would soon become public. In our subsequent comments, we were very dear that the Koreans had made a major advance, when compared with our own achievement.

We believe the strong interest in our work was not driven primarily by a parochialism that affords prominence to local news, but by the ongoing ethical debate. It is the ethics of human nuclear transfer that keeps embryo research high on the agenda of the UK press and public, not the science. We cannot avoid the resulting close and continuous scrutiny, nor should we.

AlisonMurdoch ${ }^{\star}$, Miodrag Stojkovic $\uparrow$

*Newcastle Fertility Centre at Life, Times Square, Newcastle upon Tyne NE1 4EP, UK
†Centre for Stem Cell Biology and Developmental Genetics, University of Newcastle upon Tyne, International Centre for Life, Central Parkway, Newcastle upon Tyne NE1 3BZ, UK

\section{Misconduct: lower ranks take most of the blame}

SIR - The Commentary article by Brian C. Martinson and colleagues, ${ }^{\alpha}$ Scientists behaving badly" (Nature 435, 737-738; 2005), highlights the need for an appropriate response in order to preserve good science practices at the institutional level. Although formal guidelines exist for misconduct investigations in universities, there are no checks or balances, or even public scrutiny, to ensure that the institution behaves appropriately. Ideally, universities should hand over authority to enforce good science guidelines to an independent body of informed, non-partisan reviewers unaffiliated with the institution under investigation.

Graduate students, postdoctoral fellows and junior research associates are toofrequent casualties of self-policing by institutions investigating scientificmisconduct cases. They are often less culpable than their senior colleagues, but naive about the convoluted investigatory process. A December 2004 newsletter from the US Office of Research Integrity (ORI) documents this disparity, revealing that just $15 \%$ of full professors were found guilty of fabrication, falsification or plagiarism (FFP) between 1994 and 2003, whereas junior researchers were held accountable $61-77 \%$ of the time. Compounding this rank bias, university misconduct inquiries are rarely conducted openly, yet still comply with ORI guidelines. This secrecy makes it difficult to protect the rights of junior whistleblowers.

It is interesting to learn from the survey by Martinson and colleagues that senior investigators seem more ready to admit indiscretions such as data duplication or inaccurate authorship delegation than FFP. It would be interesting to ask scientists in a misconduct survey about their willingness to disclose minor indiscretions and correlate their responses with rank. Like the recent ORI report, this would probably reflect the relative protection that a senior researcher's status provides.

Shawn G. Clouthier

Comprehensive Cancer Center, University of Michigan, 1500East Medical Center Drive, 6410 CGC, Ann Arbor, Michigan 48109-0942, USA

Contributions to Correspondence may be submitted to corres@nature.com.

They should be no longer than $\mathbf{5 0 0}$ words, andideally shorter. Published contributions are edited. 